Revue de l'Institut des langues et cultures

d'Europe, Amérique, Afrique, Asie et Australie

31 | 2018

Récits fictionnels et non fictionnels liés à des

communautés professionnelles et à des groupes spécialisés

\title{
La FASP jurídica en España: emergencia de un género global
}

Legal FASP in Spain: Emergence of a Global Genre

La FASP juridique en Espagne : émergence d'un genre global

\section{Thierry Nallet}

\section{OpenEdition}

\section{Journals}

Edición electrónica

URL: http://journals.openedition.org/ilcea/4686

DOI: 10.4000/ilcea.4686

ISSN: 2101-0609

Editor

UGA Éditions/Université Grenoble Alpes

Edición impresa

ISBN: 978-2-37747-043-3

ISSN: $1639-6073$

\section{Referencia electrónica}

Thierry Nallet, "La FASP jurídica en España: emergencia de un género global », ILCEA [En línea],

31 | 2018, Publicado el 06 marzo 2018, consultado el 01 mayo 2019. URL : http://

journals.openedition.org/ilcea/4686 ; DOI : 10.4000/ilcea.4686

Este documento fue generado automáticamente el 1 mayo 2019.

(C) ILCEA 


\title{
La FASP jurídica en España: emergencia de un género global
}

\author{
Legal FASP in Spain: Emergence of a Global Genre \\ La FASP juridique en Espagne : émergence d'un genre global
}

Thierry Nallet

1 Durante las últimas décadas del siglo xx, un nuevo género realista y popular, que se sostiene en una tensión narrativa propia del thriller a la vez que representa un ámbito profesional determinado, se desarrolló muy particularmente en las ficciones del mundo anglosajón. Este género que se ha consolidado en este siglo como "thriller especializado" ha recibido el nombre de "ficción con sustrato profesional" y se conoce por su acrónimo FASP (del francés, "Fiction à substrat professionnel"). El reconocimiento del género que vamos a analizar, hoy incuestionable, permite aclarar la naturaleza y las implicaciones de numerosas obras de éxito y resulta muy útil a la hora de contemplar la narrativa actual.

2 Partiendo de la cuestión sobre si efectivamente existía este género en España, empezamos a investigar sobre la FASP en este país, desde múltiples perspectivas, ateniéndonos primero al fenómeno del best seller, antes de adentrarnos en novelas claramente especializadas y presentadas como tal. Encontramos novelas muy variadas, de autores de éxito en ciertos casos, que trataban de un ámbito especializado y pudimos comprobar que el fenómeno empezó en España a finales del siglo xx. Sin embargo, en esta primera etapa de investigación, la dimensión autorreflexiva y la teorización por parte de la comunidad literaria -autores, editores, lectores y críticos- nos parecían fundamentales para dictaminar sobre la existencia de un género nuevo más allá de la praxis individual de algunos autores. Por eso, optamos por indagar en la novela de Abogados sobre la que va a versar esta reflexión acerca de la FASP en España y, más precisamente, del subgénero de la FASP jurídica. El descubrimiento del "Premio Abogados de Novela" constituye una ocasión inédita de esclarecer los fundamentos y la realidad del género en España, e indagar así en la poética específica de los autores españoles que adaptan el género a su idiosincrasia. 
3 Este artículo tiene varios objetivos, uno teórico que consiste en buscar las características de un subgénero de la llamada FASP que se desarrolla a nivel mundial a partir de un foco anglosajón, y otro lingüístico-cultural que se centra en la representación ficcional de los abogados y de sus discursos. Para dilucidar el complejo entramado entre género y lenguacultura de especialidad, primero repararemos en una cuestión de campo, más precisamente en la interrelación e intersección entre Derecho y Literatura, dos disciplinas muy diferentes pero unidas desde hace siglos, probablemente desde los mismos orígenes de la abogacía, pero también en cierta medida de la creación literaria si pensamos en la tragedia griega por ejemplo.

Numerosos trabajos se han interesado en este tema tan fecundo, conocido en inglés bajo el rótulo de "Law and Literature", desde perspectivas múltiples destacadas por las preposiciones que sirven para poner en relación uno y otro campo: Derecho en la Literatura, Derecho de la Literatura, Derecho como Literatura, etc. Al respecto, José Calvo González plantea estas relaciones de forma sintética en uno de sus artículos más interesantes "Derecho y Literatura. Intersecciones instrumental, estructural e institucional":

Las intersecciones entre lo jurídico y lo literario se articulan a través de cierta clase de sintagmas gramaticales que actúan como puente, organizadas concretamente mediante tres preposiciones (en, indicando lugar; de, denotando pertenencia; con, expresando la circunstancia con que algo se ejecuta o sucede) y un adverbio modal ( como, es decir, a modo de, según, en tanto que o tal que, apuntando tipos de cotejo que van desde adyacencia hasta simetría). (2007: 309-310)

5 Esas fórmulas suelen privilegiar como primer término del binomio la materia seria, el Derecho, aunque se podrían invertir todas esas expresiones haciendo hincapié en el interés de lo literario para el Derecho, al igual que para otras muchas materias extraliterarias. Frente al papel sintetizador de la Literatura, el Derecho conserva unas características menos endebles y, por lo tanto, más distintivas que hacen que cualquier documento, incluso la pura ficción, se considere como dependiente del campo jurídico siempre que el tema esté tratado de forma seria y documentada. Desde este postulado, la ficción puede cobrar una función documental, a modo de testimonio imaginario. Esta primacía del Derecho, o por lo menos la importancia de este punto de vista incluso en la literatura afín al derecho, hace que unas obras ficticias con una trama popular resulten totalmente híbridas y merezcan una atención especial a nivel teórico y pragmático².

\section{Derecho y Literatura}

6 Nuestra reflexión tiene como punto de partida la conjugación, más allá de la confrontación, de dos campos distintos. En el siglo xx, la corriente Law and Literature ha favorecido una relectura y reinterpretación de textos literarios antiguos y de grandes obras realistas de siglos pasados. Unos críticos realizaron entonces trabajos para teorizar una relación que, como en otros casos de hibridación de tipo "Filosofía y Literatura" o "Historia y Literatura", necesita una puesta en orden para entender cómo se entrelazan unos dominios a priori independientes.

7 Primero, el Derecho y la Literatura funcionan de forma idéntica con un "relato" de los hechos, a partir de los cuales se aplican unas normas o leyes y de los que, después de la necesaria "interpretación" según Dworkin (1997), se saca un juicio. Asimismo, son dos prácticas sociales en las que tienen mucha importancia la referencia, el punto de vista y la 
“imaginación” (Nussbaum, 1997). De hecho, la práctica tanto jurídica como literaria descansa en casos concretos. La evaluación y la interpretación forman parte del oficio de jurista, pero también del escritor. Cabe subrayar, además, que la lectura es un ejercicio imprescindible para jueces o legisladores, y que muchos textos, empezando por los códigos de ley, están escritos con un nivel de atención a las palabras muy alto. Los textos literarios, por otra parte, han interesado a los especialistas del derecho, al igual que las sentencias ya falladas y creadoras de la jurisprudencia, como una praxis reflexiva del derecho. La representación literaria, por la reflexión y reflexividad que conlleva, con el reflejo que brinda, introduce una dimensión filosófica interesante para el ejercicio jurídico.

8 En este sentido, la literatura desempeña un papel primordial al permitir a la imaginación crear ficciones que cuestionen el límite entre lo legal y lo justo, como bien explica François Ost (2004). Este punto de vista que hace hincapié en el utilitarismo de los textos de ficción subraya su interés para la justicia. Las pasiones ficticias permitirían hacer un mejor uso de la razón, de la misma forma que la ley abstracta y ciega se plasma de forma concreta y reflexiva en ficciones ejemplares que puedan enseñar las paradojas y la complejidad de unas vidas.

No obstante, si la literatura permite ofrecer conocimientos nuevos es a través de su talante heurístico, concretando la ley abstracta y general y poniendo a prueba la conciencia individual frente a "casos de conciencia". Solo la literatura reúne las tres dimensiones de la mímesis que permiten una comunicación entre percepciones distintas: los fenómenos dados que prefiguran, la representación artística que configura y el lectorespectador que refigura, como bien ha explicado Paul Ricœur (1983-1985). De hecho, la jurisprudencia no es otra cosa que una interpretación innovadora de la ley, tal vez anunciadora de su futuro cambio.

10 A pesar de la presencia de la especialidad jurídica en la literatura, esta sigue teniendo las mismas funciones esenciales. Al hacer participar a los lectores a los que tiene que gustar, la literatura cumple el propósito clásico de "enseñar deleitando". Las funciones de divertir y al mismo tiempo de enseñar representan el motor de la lectura de novelas que transcurren en un ámbito profesional. Pero otra función es también fundamental y consiste en la proyección e identificación humana que conduce a la catarsis. La literatura que integra el derecho, especialmente la FASP jurídico-judicial como lo veremos, se caracteriza por cierta teatralidad, con diálogos, escenarios e intercambios múltiples.

11 El uso de la lengua constituye la principal diferencia sustancial entre los dos campos, ya que la lengua de especialidad no cumple la misma función en el ámbito jurídico y en la creación literaria. Además, mientras que la lengua de los textos especializados se fundamenta sobre todo en la terminología y otras locuciones hechas, la literatura da cabida a todos los registros del idioma e incluye expresiones y refranes populares así como interjecciones, argot, improperios, etc. En definitiva, hace un uso de la lengua global, una lengua solo virtualmente especializada, coloquial, vulgar o poética. Por otra parte, y consecuentemente, la lengua inserta en la vida profesional está supeditada a la cultura de especialidad. Más allá de los signos lingüísticos, el reflejo de una realidad cultural y profesional se apoya en unos escenarios, unos procedimientos, unos usos sociales del todo reales.

12 La movilidad de las fronteras del dominio de especialidad y los usos diferentes de cada miembro de la comunidad de discursos obligan a una delimitación de la ficción en función de criterios precisos: el del ámbito profesional es decisivo para la FASP. Su 
representatividad depende de muchos factores que justifican los criterios propuestos por el crítico francés Michel Petit.

El marco teórico de la FASP propone un enfoque nuevo sobre el fenómeno de encuentro entre Derecho y Literatura. A partir de un rasgo genérico antiguo, que nació al mismo tiempo que la literatura realista o referencial, Michel Petit identificó y codificó un género que inscribió en la época contemporánea, en la que la ficción ya se entendía de forma global, enseñando así el parentesco entre literatura, televisión y cine. El nacimiento de este género anglosajón se remonta a los años 1980-1990. Su identificación descansa en la convergencia de un abanico de características que la FASP ha de cumplir. Aunque el acrónimo proceda del francés, la perspectiva de Michel Petit y sus continuadores, entre los que destaca Shaeda Isani, depende mucho del inglés de especialidad llamado ASp en francés, "Anglais de spécialité", equivalente del ESP, "English for specific purposes".

Una de las definiciones más completas de la FASP, enunciada por Michel Petit ya desde el año 2000, permite destacar los cuatro requisitos para que una obra pertenezca al género:

Puede considerarse como perteneciente a la FASP cualquier texto de ficción comercial, de mucho éxito, (i) que participa generalmente del thriller especializado (jurídico, médico, tecnológico, etc.), (ii) que se vale de un ámbito profesional particular no solo como marco global del relato sino también y sobre todo como una de las fuentes principales de los resortes de la intriga, (iii) expresado en una lengua que reproduce las prácticas lingüísticas (léxicas y discursivas) de este medio, y (iv) generalmente escrito por un autor cuya pertenencia o cuyos vínculos se reivindican explícitamente. ${ }^{2}$

15 Su naturaleza dual e híbrida no deja de crear asimismo una tensión, puesto que la FASP constituye una ficción especializada, es decir, una ficción que se fundamenta en la realidad y la acerca a la novela histórica o testimonial. Cada elemento característico de la FASP mantiene así una relación sinecdóquica con el todo, la lengua de especialidad dentro de la lengua general, la vida profesional dentro de la vida a secas, etc. Por consiguiente, la intriga y su desenlace descansan en lo especializado como culmen del relato tanto psicológico como sensacionalista.

Por otra parte, la FASP española podría ser analizada en términos de confluencia genérica y plurigenericidad. En efecto, la riqueza de esta novela se debe a su parentesco con otros géneros de los que se inspira y que ofrecen un marco narrativo eficaz al relato, como el thriller, la novela de enigma o incluso psicológica o sentimental. Esta cercanía con otros géneros tiene como efecto un juego de reflejos, de la misma forma que la novela refleja lo especializado, lo rodea sin llegar a identificarse totalmente con él. ¿Aleja esta mímesis a la FASP de la autenticidad? No forzosamente, aunque constituya sin duda uno de sus límites. La cuestión de la representación realista participa al fin y al cabo de una reflexión global sobre la mímesis, como la que Paul Ricœur desarrolló en Tiempo y narración.

17 La FASP jurídica constituye sin duda el subgénero de FASP dominante. La proliferación de novelas pertenecientes a este género se explica por la tipología de sus protagonistas, de las relaciones que los unen y de los lugares y procedimientos que ofrecen una cronología a una trama que se entreteje con otros temas. La enciclopedia especializada (Van der Yeught, 2016) del campo jurídico formaría un marco superior que pudiera dar cabida a otros subtemas de cualquier índole (médica, técnica, literaria, académica, artística, etc.). Estas otras enciclopedias conformarían a su vez nuevos sustratos o, en muchos casos, más bien "adstratos", caracterizándose estos por un trabajo documental menos vinculado con una experiencia propia, cercana al testimonio, que el "sustrato" propiamente dicho. 

tipos o especies que dependen del protagonista y de su medio profesional: el juez, el abogado, el policía o el forense son los tipos más frecuentes. El abogado es la figura ideal de la FASP jurídico-judicial por su papel de intermediario y su función de mediación. Además, a modo de mise en abyme, el relato puede contener a su vez una especie de legal fiction con la narración intercalada de un abogado o en la restitución de los hechos.

Llegados a este punto, cabe justificar la asociación de dos adjetivos muy parecidos, cercanos pero que se refieren a dos niveles complementarios de la representación de la justicia: lo jurídico, que viene del latín jus, es decir, el "derecho", se refiere a todo lo relativo a este campo y muy en particular al lenguaje y la terminología de esta especialidad, mientras que lo judicial, como su raíz etimológica judicium indica, caracteriza la cultura del "juicio" y de los procedimientos. Estos dos aspectos van parejos en la FASP, al estar íntimamente unidos el fondo y la forma, la intriga y la trabazón novelesca, la cultura y la lengua.

La FASP puede también ser propiamente jurídica (Legal FASP) o simplemente parajurídica (Law-related FASP). Esta diferencia, no siempre muy clara en las obras, permite distinguir las novelas en las que todo depende de lo jurídico que constituye in fine un sustrato, de las obras que tienen una simple relación con lo jurídico representándolo, convirtiéndose este en un adstrato ficcional. La denominación más amplia de esta ficción, "FASP jurídicojudicial", permite englobar sin duda alguna todas las novelas que vamos a examinar.

21 Este tipo de novelas se ha desarrollado sobre todo en Norteamérica con autores tan prestigiosos como John Grisham, tal vez el mayor representante de la FASP jurídica por haber explorado toda la extensa realidad de la justicia anglosajona. En este sentido, la narrativa jurídico-judicial ha dado lugar no solo a novelas sino también a adaptaciones cinematográficas de las mismas. Por ejemplo, el éxito de la película The Firm, inspirada en la novela epónima de Grisham, participó en la difusión y reconocimiento del género. Sin lugar a dudas, la FASP reúne un conjunto de obras tanto literarias como audiovisuales o incluso multimodales hoy, gracias a los avances tecnológicos. Asimismo, más tarde, series de televisión tan famosas e importantes como Ally McBeal a finales de los años 1990 recibieron la aceptación de un amplio público, al tiempo que crecía la fama de una producción cultural global y se multiplicaban las ventas, o superventas, de unas novelas típicas del género de la FASP. Estas se comercializaban entonces poniendo de relieve en la portada y contraportada su condición de best seller y de thriller judicial o jurídico.

En España, a pesar del gran número de abogados y letrados ${ }^{3}$, ya que compiten dos palabras para abarcar la variedad de realidades profesionales, no eran frecuentes en las letras hispánicas las novelas que tuvieran al abogado como protagonista, y menos aún como protagonista dentro de su propio medio profesional. Por eso, el premio que ahora cabe presentar y analizar resulta lo suficientemente original como para merecer un estudio detenido y específico.

\section{Premio Abogados de Novela}

23 Al descubrir que existía una colección española de novelas formada en torno al Premio Abogados de Novela, nos adentramos en una línea creativa nueva, bastante original y apta para suscitar el interés de los lectores. Este premio literario reciente -data de 2010- 
pone de manifiesto no solo la emergencia del género de la FASP jurídica en España sino también su fomento y reconocimiento en los últimos años ${ }^{4}$. llamada a manuscritos inéditos formulada por los responsables dependientes tanto de la editorial Martínez Roca como del Colegio de Abogados, es decir, agentes corporativos y editoriales que fueron al origen de este concurso literario. De hecho, la presentación del premio indica de forma explícita el parentesco del género con la FASP anglosajona:

La creación de este premio intenta consolidar un género, el del thriller judicial, en auge en el mundo anglosajón y que en España no se ha desarrollado de la misma forma.

Novelas inéditas que giran en torno al amplio mundo de la abogacía y que enganchen a un amplio público lector son las llamadas a obtener este galardón.

Desde su creación la cuantía del premio es de 50.000 euros a la novela que, por unanimidad o mayoría de votos, el jurado considere con mayores merecimientos. En la actualidad este es uno de los premios con mayor dotación económica. (escritores.org, 2014)

Los organizadores del premio, además de las Ediciones Martínez Roca, pertenecientes al Grupo Planeta, son dos grupos profesionales garantes de la calidad referencial del concurso: por una parte, el Consejo General de la Abogacía Española, y por otra, la Mutualidad de la Abogacía. Estas dos entidades forman parte de las más importantes para la profesión de abogado, aunque el gran público desconoce su papel preciso. Por eso, al tiempo que se presenta el premio, se destacan las misiones esenciales de estos organismos gremiales, por ejemplo en la página web de la convocatoria:

El Consejo General de la Abogacía Española es el órgano representativo, coordinador y ejecutivo superior de los 83 Colegios de Abogados de España (que agrupan a un total de 130.000 abogados ejercientes y 54.500 no ejercientes) y responsable de ordenar el ejercicio profesional de los abogados y velar por el prestigio de la profesión. (abogacia.es, 2014a)

Se trata, de hecho, de un organismo más bien público que ofrece un marco al ejercicio del oficio. Es un Consejo que, por así decirlo, reagrupa en su diversidad a todos los abogados o letrados españoles.

El segundo organismo es privado, pero también protege a los agentes de la abogacía ofreciéndoles esta vez servicios de seguros:

La Mutualidad de la Abogacía es la entidad aseguradora propia de los abogados, que opera sin ánimo de lucro para ofrecerles la posibilidad de satisfacer todas sus necesidades de previsión, ahorro y seguro. Cuenta con la confianza de más de 150.000 mutualistas, gestiona un volumen de ahorro de 2.650 millones de euros, invertidos en activos financieros e inmobiliarios. Se encuentra situada entre las 15 primeras entidades aseguradoras de España y en el primer lugar del ranking como mutualidad de previsión social. (abogacia.es, 2014a)

El mismo oficio reúne a un conjunto de personas diferentes que obran por la justicia. Esta comunidad de discursos jurídicos y actividades judiciales permite una visión común de la labor del abogado que comentaremos más adelante.

Sin embargo, lo más interesante estriba en el marco literario ofrecido por el reglamento del premio, titulado "Bases del premio Abogados de Novela", que tiende a acercar las novelas susceptibles de ser galardonadas a la definición de la FASP como íntimamente vinculada al "sustrato profesional":

1.- Podrán optar al premio todas las novelas inéditas presentadas que versen sobre

el mundo en que se desarrolla la actividad de los abogados, protagonizadas por 
abogados, que ayuden al lector a profundizar en el conocimiento de esta profesión y sus ámbitos de actuación, valores, proyección y trascendencia social de su función. (abogacia.es, 2014b) prime, permite identificar el género de la FASP. Tanto el premio como el género tienen como criterio principal el protagonismo de la profesión y, por eso, todas las novelas galardonadas pertenecen a priori a este género que va más allá del thriller.

31 Asimismo, cualquier premio literario conlleva una difusión y publicidad fuera de lo común. Por lo tanto, las novelas editadas han de respetar las expectativas en cuanto a calidad e interés impuestas por el Grupo Planeta, en particular las Ediciones Martínez Roca, especializadas en la novela histórica y otros géneros populares, como la fantasy o las biografías. Esta narrativa se dirige a un público de masas. La difusión de estas novelas, pues, está prevista para hacerse a gran escala, a golpe de recursos comerciales capaces de realzar la dimensión jurídica y especializada de novelas creadas ad hoc. Uno de los riesgos que conlleva el incentivo económico puede ser la aplicación de recetas prestadas, inspiradas en otros best sellers, a la materia jurídica descuidando la calidad literaria de la trama ${ }^{5}$. Ya no sería más que una colocación de productos, unos libros estereotipados encargados a través de un galardón interesante. No obstante, este código comercial, a pesar de su influencia en el número de ventas, no explica el interés por el género por parte del "gran público".

En este sentido, resulta muy importante el paratexto, y en especial la tapa de las cuatro novelas que hemos escogido. Nuestra elección se ha hecho en función de la actualidad de unas ficciones inscritas en las realidades jurídicas de hoy. Por tanto, son ficciones marcadas por lo real. De hecho, hemos descartado las novelas más históricas que, pese a su interés desde la perspectiva de la intersección entre Derecho y Literatura, no permitían la misma representación del mundo laboral contemporáneo. Así, el corpus escogido consta de cuatro títulos premiados respectivamente en 2010 (La prueba), 2012 (El bufete), 2013 (El jurado número 10) y 2015 (La mediadora). Es necesario ahora examinar estas novelas para saber si efectivamente pertenecen a la FASP o en qué grado de FASP se sitúan, más allá del premio que de por sí justificaría la denominación.

\section{Novelas premiadas}

La prueba de Carmen Gurruchaga (1955- ) es la primera novela en haber sido galardonada. Su construcción muy lograda refleja bien el mundo de los abogados y cierto número de especializaciones jurídicas. Además, su título remite a diferentes "genericidades" o funcionalidades genéricas complementarias, desde el relato de investigación hasta la acusación judicial. Por otra parte, la prueba es también un objeto referencial, una moneda, un doblón antiguo.

Su autora es periodista, de origen vasco, especialista en ETA, afincada en Madrid después de haber sido víctima de un atentado, más precisamente de un ataque con explosivos en su propio domicilio en el País Vasco. Se trata de su primera novela, después de cierto éxito en los medios de comunicación españoles (escritos y audiovisuales) y por sus ensayos sobre la organización terrorista vasca ETA. Ha realizado una labor de documentación muy seria y ha imaginado una trama sorprendente adecuada para satisfacer el gusto del gran público (dinero, poder, guardia de los niños, violencias conyugales, prostitución, bufetes rivales, política, etc.). La foto de la tapa representa a la 
abogada protagonista de la novela. Se trata así de una FASP propia del siglo XXI, siglo en el que muchos periodistas escriben a partir de una base documental fuerte. El género novelesco se está modificando en contacto con los medios de comunicación y la FASP va evolucionando, haciendo que se confundan cada vez más sustrato y adstrato.

Borja Martínez-Echevarría (1975- ) es también periodista, aunque cursó la carrera de derecho en la Universidad Complutense de Madrid y tiene así un conocimiento directo de la Abogacía. Ha trabajado para un suplemento "jurídico" del periódico Expansión. Participa actualmente en un programa de radio titulado Abogados y colabora en una empresa de consejo estratégico para las sociedades de abogados. Su pericia en el análisis del funcionamiento opaco del mundo de los bufetes hace de él un experto en información jurídica.

36 Su primera novela se titula precisamente El bufete, recordando novelas y películas que tienen como escenario este ámbito laboral, y describe los entresijos del trabajo en el seno de un despacho de abogados especializado en el mundo de los negocios. Al final de la novela, el epílogo "agradecimientos" se dirige especialmente a los abogados que el autor ha consultado:

Son muchos los abogados que me han instruido en asuntos técnicos y jurídicos para escribir la novela. A todos ellos, mi agradecimiento sincero. Cualquier error, equivocación, incongruencia o flagrante desatino en materia jurídica en la trama es error mío y solo mío, puesto que no puse la necesaria dedicación en mis estudios de derecho en la "Complu". (2012: 315)

La fotografía de la tapa representa al tipo de abogados especializados en los negocios descritos en la novela. Este abogado muy trabajador hace soñar por las cantidades importantes de dinero que puede ganar, asesorando en operaciones financieras delicadas, como una OPA hostil, cuya definición aparece en la novela: "Una OPA hostil era la forma técnica de referirse a la oferta pública de adquisición que una empresa hacía para comprar las acciones de otra compañía en la que estaba interesada" (2012: 119). Esta FASP con mucha tensión se parece bastante al modelo anglosajón en su imaginario y recuerda mucho a la novela o película The Firm.

Reyes Calderón (1961- ), profesora de economía en la Universidad de Navarra, apasionada por la Filosofía y el Derecho, se ha convertido en una novelista de éxito con novelas de investigación, cercanas al género policíaco, con la figura recurrente de una juez llamada Lola MacHor. Su perfil como escritora es más nítidamente afín a la FASP por su condición de especialista en la materia y el parentesco bastante obvio de su obra con el género anglosajón que reivindica. La novela premiada en 2013 titulada El jurado número 10 se estructura alrededor de la figura de los abogados, por quienes siente una auténtica admiración como lo indica en la coda final de su novela a modo de agradecimientos:

[...] soy hija de jurista; una de mis hermanas es magistrada; otros dos, abogados, y una de mis hijas estudia Derecho. Tengo en mi haber que una juez ha protagonizado mis últimas cinco novelas; sin embargo, aún tenía una deuda con el fascinante mundo de los abogados, grandes desconocidos de la literatura española, hasta la llegada de este premio: me enorgullece formar parte de su historia. (2013:510)

La autora aprovecha la ocasión para agradecer a todas las personas que la han ayudado en sus búsquedas documentales, sus "expertos" que ejercen como abogados, presidente del Tribunal Supremo de Justicia de Navarra, policía nacional, forense, etc. Lo que escribe es un "thriller judicial", una auténtica FASP influenciada a ojos vistas por la tradición norteamericana, tanto de la novela negra como de la novela policíaca, con la presencia de personajes tradicionalmente excéntricos: un abogado fracasado y su única socia, una 
secretaria muy especial, confrontados a un tráfico de droga, un millón de euros y un asesinato inexplicado.

El modesto abogado de provincias que pesa unos 138 kilos al principio de la novela y su llamativa secretaria que viste de forma provocadora están involucrados de forma torpe e involuntaria en un caso sobre el que tienen que investigar para salvarse la vida. Todo desemboca en un juicio cuyo fallo depende de un juez, pero sobre todo de un jurado popular. Los jueces legos, o sea no profesionales, son nueve en España. Por lo tanto, el décimo no puede ser sino virtual y participativo: no solo el abogado narrador cuyo testimonio constituye la novela en un marco literario próximo al diario íntimo, sino también el propio lector, testigo de una investigación trepidante y del desarrollo paralelo de diferentes casos judiciales secundarios. El lector tiene mucha importancia en El jurado número 10 como co-protagonista, lo que acerca también esta novela al fenómeno de "bestsellerización" que consiste básicamente en satisfacer los deseos de la mayoría de los lectores, ofreciendo diferentes niveles de lectura, en un mercado editorial limitado, de pocas obras vendidas a gran escala.

41 Sin embargo, la calidad literaria de El jurado número 10 acompaña la calidad del contenido jurídico. El engarce narrativo explica la presencia de la escritura en la mayor parte de las novelas, según la técnica de mise en abyme destacada por Shaeda Isani (2010), es decir, la representación de la escritura de la novela dentro de la novela. Este recurso, antes que nada un recurso de la nueva narrativa del siglo xx se ha convertido en un topos literario al que puede recurrir la novelística popular actual. Esta novela es a la vez la más técnica y la mejor construida, hasta el extremo de conseguir un alto nivel de literariedad. Gracias a su complejidad y completud, es la novela de nuestro corpus que alcanza el mayor grado de FASP; el juicio presente en la segunda parte de la novela de Reyes Calderón está muy logrado.

42 Jesús Sánchez Adalid (1962- ) se doctoró en derecho en la Universidad Complutense de Madrid y ejerció de juez durante dos años. En la actualidad se ha especializado en derecho canónico y es profesor de ética en un centro universitario. Es conocido y reconocido por sus novelas históricas que obtuvieron mucho éxito y aceptación entre los lectores españoles, como El alma de la ciudad o Alcazaba. Recibió numerosos premios antes de conseguir el "Premio Abogados de Novela" por La mediadora, que narra el divorcio de Mavi y Agustín. La novela plantea la labor de mediación, creciente en España, con abogados especializados en el tema. La prensa ha recalcado con ocasión de la publicación de la novela el que España sea el quinto país del mundo con más divorcios, lo que no deja de plantear problemas legales. El relato refleja la vida de dos enamorados cuyos caminos se han alejado hasta la dolorosa ruptura. Maite, abogada especialista en mediación matrimonial, trata de desempeñar un papel reparador y a la vez liberador que permita a los ex cónyuges encontrar un compromiso, en particular con respecto al taller del marido que se encuentra en la casa de su mujer y la pensión compensatoria que pudiera darle su mujer, exitosa escritora.

Sus agradecimientos muestran una vez más la imagen positiva de la profesión de abogado vehiculada en la ficción:

También debo agradecer a un entrañable grupo de abogados de Mérida que me facilitaran información, con tanto afecto, y que me dedicaran su tiempo. Especialmente a mi amigo José Custodio. Todo esto es un homenaje a ellos, a su compromiso con la verdad, su amor a los principios y sus valores humanos. (2015: 268) 
A pesar de ser un relato psicológico y sentimental, pertenece a la FASP por la presencia en la trama de la intriga judicial y la reproducción de documentos jurídicos, como el fallo de la primera sentencia mandado por correo electrónico a Mavi. El quinto punto del fallo explica lo que es una "pensión compensatoria":

Quinto. El presupuesto fáctico para el nacimiento de la pensión compensatoria, tal como expresa el artículo 97 del Código Civil, es el desequilibrio económico que para uno de los cónyuges pueda significar la separación o el divorcio en relación con la posición del otro. [...] El fundamento de la pensión compensatoria descansa pues en el equilibrio que debe subsistir entre los cónyuges en los casos de ruptura matrimonial, de forma que ninguno de ellos se vea afectado, desde un punto de vista material, en el estatus que mantenía al tiempo de la convivencia. (2015: 44)

La presencia de la lengua de especialidad es muy importante a la hora de evaluar la FASP. La ficción inmersa en la cultura judicial se apoya en la lengua jurídica, no solo de forma instrumental $u$ ornamental para conferir mayor realismo a la acción, sino también como agente mismo de la acción y de los resortes de la intriga. En cierto modo, el aspecto formal caracterizado por el uso lingüístico dispar, con una heterogeneidad entre diferentes niveles de lengua que ya hemos subrayado, constituye un factor de genericidad muy fuerte en el caso de la FASP.

\section{Renovación del género: lengua y cultura}

Cabe subrayar que la lengua de especialidad del derecho está presente en la FASP jurídica española a diferentes niveles: en los textos de ley reproducidos, relativamente poco numerosos, y más a menudo en las sentencias u otros juicios que configuran la intriga; en la comunicación profesional, muy importante en el oficio de abogado, con entrevistas entre abogados y clientes, intercambios entre compañeros de profesión bajo forma de correos electrónicos o conversaciones, etc.; en la parte narrativa que depende de un narrador observador, que este sea omnisciente o no.

La divulgación se hace mediante definiciones o explicaciones como las ofrecidas por el abogado a su secretaria o a sus clientes en El jurado número 10: sobre los "considerandos" por ejemplo en el procesamiento de un caso. En La prueba, aparece el procedimiento del "concurso de acreedores" o de quiebra. Se explican en La mediadora las nociones de "mediación" y "jurisprudencia". Pero la fraseología jurídica es perceptible de la misma forma en el mismo relato que hace el abogado de El jurado número 10 recordando varias veces lo que pasó el "día de autos", es decir, el día de los hechos, según un giro utilizado en el recinto de los tribunales.

Una de las particularidades de la lengua de especialidad presente en las novelas es su integración en el seno de una construcción narrativa que es puramente literaria. Se podría evocar el alegato del abogado de El jurado número 10 en el capítulo 23 de la novela. De hecho, la polifonía de la novela teorizada por Bajtín ${ }^{6}$, con voces autónomas, permite ese dialogismo y esa diversidad de las lenguas: de la lengua corriente y vulgar a la jerga de la profesión. El abogado representa esta figura de mediación entre la lengua soez de los clientes y el lenguaje del derecho de los juristas, permite también este paso importante de lo escrito a lo oral y de lo oral a lo escrito. De igual forma, la novela tiene una función de mediación idéntica, iniciando al lector en la cultura jurídica por la ficción. 
49 Esta observación de la FASP jurídico-judicial nos conduce a un replanteamiento del género en España a fin de cuestionar sus características y la adaptación que ha sufrido en las letras ibéricas.

El "Premio Abogados de Novela", desde la publicación de la primera obra galardonada, ha puesto de relieve explícitamente la genealogía del género, que sufre sin embargo un fenómeno de aclimatación en España. La emulación cultural está claramente indicada en la contraportada de La prueba, propia del merchandising clásico de las novelas populares de las que se esperan récords de ventas: “A la altura de los grandes del género norteamericano, una autora española, Carmen Gurruchaga, se adentra en el thriller judicial para demostrar que nuestra realidad puede ser tan apasionante o más que la de fuera de nuestras fronteras." Este paso genérico permite cierta intertextualidad, ya que el modelo norteamericano está subyacente y funciona incluso como segundo sustrato, esta vez formal y no temático como el sustrato profesional. La referencia insoslayable para muchos autores es John Grisham, en especial para Reyes Calderón y Borja MartínezEchevarría, quien escribe en su blog la admiración que siente hacia el autor al que considera como un modelo de perfección:

Hace varios años me enganché a las novelas de intriga de abogados que escribe John Grisham. Me atrapó con El jurado y, desde entonces, he leído casi todas sus novelas. Con el paso de los años, y especialmente desde que me dedico al asesoramiento a despachos de abogados, he ido descubriendo en los libros de Grisham pequeñas "píldoras" de sabiduría que demuestran lo bien que conoce el mercado jurídico y la forma de trabajar en los bufetes. [...] Y, en muchos casos, se puede aprender mucho sobre gestión de despachos. (2015)

51 Este ha explorado en su novelística todo el campo judicial y su lectura fue un incentivo para escribir novelas jurídicas.

En cuanto a la adaptación cultural, lo que sobresale del corpus de las novelas escogidas es la inserción de procesos del ámbito profesional en la cultura española. Por ejemplo, se puede evocar todo lo que se refiere a las costumbres locales (horarios, platos, bebidas, charlas de sobremesa, importancia de los bares, etc.), es decir, la vida misma como marco superior de la novela. Asimismo, las diferencias regionales y los tópicos relativos a cada región y personaje en función de su lugar de origen (vasco, andaluz, etc.) son fuentes de humor. Así pues, la relación del género con los estereotipos resulta muy interesante. En efecto, más allá de la FASP, se encuentra la literatura popular, más nacional que internacional con ciudades muy reconocibles, por ejemplo Madrid, o calles conocidas -o desconocidas - con la presencia de la ONCE, la Organización Nacional de Ciegos Españoles que vende cupones en toda España. La FASP puede gustar a todos los lectores por su carácter lúdico al yuxtaponer paradójicamente la proximidad de la vida española cotidiana con la excepcionalidad de una situación jurídica que les es ajena.

El tono particularmente realista de novelas "locales" se debe a su dimensión socioeconómica, con la aparición de mafias chinas, migrantes en centros de retención, droga, prostitución, aunque lo que más llama la atención es la crisis económica y financiera en el contexto actual del liberalismo. Así la FASP tiene cierta dimensión de novela social, cercana a la novela negra norteamericana. Además, estas novelas dan cobijo a unas grandes cuestiones de sociedad, como el machismo cotidiano, las relaciones entre hombres y mujeres, la violencia conyugal, y en general las violencias perpetradas contra mujeres, pero también la obesidad de uno de los personajes. El feminismo de una abogada joven en La prueba podría indicar que se busca un cambio de imagen de los abogados, ya 
no solo varones, o que el público objetivo son mujeres lectoras que se pueden identificar con esa abogada rodeada de hombres. Este aspecto de representación de la profesión en los dos sentidos de la palabra -tanto reflejo como ejemplaridad- constituye tal vez un criterio fundamental para el otorgamiento del premio, al tender este hacia una visión positiva del abogado, aquí en su componente social y reivindicativo, pero también en su deontología, lo que estudiaremos luego.

El marco cultural español se nota también en algunas referencias específicas. Por ejemplo, en El jurado número 10, el humorismo depende a veces de conocimientos particulares como la alusión a "la secretaria de Mortadelo y Filemón" (2013: 53). Esta observación recalca la capacidad de la FASP para aprovechar la puesta en relación de representaciones diferentes según un fenómeno de extensa intersemioticidad, con referencias a películas o a un tebeo en este caso. Estos elementos culturales son fundamentales para la intriga y su desarrollo, aunque el marco profesional probablemente sea el rasgo más destacado de estas novelas, lo cual subraya la importancia de la referencialidad externa.

El género, pues, se aclimata en España y la vida española que impregna todas las intrigas le da un tono diferente del original anglosajón según un efecto propio de la "aldea global". En efecto, pese al localismo, el género superior reconocible es internacional y resulta de un diálogo intercultural. En consecuencia, esta ficción experiencial y testimonial es fácilmente asimilable por el público español.

\section{Representación de la profesión de abogado}

Las figuras de los abogados españoles son muy variadas de una novela a otra, especialmente en cuanto a su especialidad o su nivel de especialización. Los campos jurídicos aludidos en el corpus abarcan el derecho civil y familiar, el derecho comercial, el derecho penal o el derecho laboral. La fuerza novelesca depende mucho de la praxis de abogados que no se sitúan en generalidades o teorías, sino que se enfrentan a casos prácticos que defender o resolver. Esta fortaleza depende también de la integración de los afectos y de las emociones en relatos que humanizan los códigos de ley, hasta tal punto que el ritmo y la tensión narrativa implican al lector a nivel intelectual y personal. Más allá de lo jurídico, está la fuerza de la verosimilitud de situaciones individuales: el divorcio en el caso de La mediadora, la investigación y el juicio en El jurado número 10, o unas situaciones conflictivas en $\mathrm{El} \mathrm{bufete} \mathrm{o} \mathrm{La} \mathrm{prueba.} \mathrm{La} \mathrm{representación} \mathrm{concreta} \mathrm{se} \mathrm{sitúa}$ en el plano de lo humano que permite enseñar la buena cara de unos abogados cuya deontología honra a la profesión, por ejemplo al rechazar algunos casos penales:

Lo que hubiera querido explicar a mi socia, y no tuve ocasión, es mi propia visión de

la profesión. Me parecía importante que comprendiera por qué no acepto

determinados casos, sin dejar por ello de creer en la justicia. (Calderón, 2013: 59)

En su conjunto, se destaca la generosidad de abogados buenos, fuera de lo común no solo por la situación excepcional que les toca vivir, sino por su capacidad de empatía y de comprensión. Jimena, en La prueba, percibe a uno de sus compañeros de bufete de la siguiente forma:

Con ese cerebro lleno de nubes, Jimena aún no comprendía cómo podía ser tan buen abogado, siempre pendiente de los plazos y del más mínimo detalle, atento con los clientes, delicado con las situaciones que lo merecían, especialmente sagaz para valorar las pruebas y encontrar el cabo suelto en cualquiera de los muchos procesos penales que acostumbraba a llevar a la vez...

Claro que, por otra parte, también desarrollaba una singular empatía. Era 
extremadamente hábil para hacerse perdonar sus faltas, y para convencer a los jurados, y para engatusar a los testigos hostiles hasta hacerles declarar aquello que jamás pensaron contar, aquello que unos instantes antes de hablar con él, completamente convencidos, negaban ante Dios y el juez. (Gurruchaga, 2010: 65-66)

La caracterización positiva del héroe novelesco no varía de una novela a otra a pesar del punto de vista que puede ser diferente; la novela realista permite penetrar tanto en la vida como en la mente de los personajes. La mayor parte de estos abogados entienden también los problemas económicos de sus clientes y trabajan sin afán de lucro. En contraste, la visión negativa de los bufetes rivales enseña la cara oculta del oficio y lo que se denuncia como malas prácticas de la profesión. El bufete plantea la eticidad de algunas prácticas profesionales que pueden incluso constituir un delito:

Alteración del precio de las cosas. Tenía un nombre y estaba tipificado en el Código Penal. Miró al frente. La fachada del Tribunal Supremo se erguía imponente frente a sus ojos. La bandera de España culminaba el edificio. Aquellas piedras con sus estatuas y volutas representaban todo lo que una vez él había querido defender. La Justicia. Le estaban pidiendo que cometiese un delito. En el fondo de su alma, quizá en un compartimento que había cerrado después de aquel verano con su primo, se revolvió la conciencia. ¿Cometer un delito? ¿Estaba preparado? (MartínezEchevarría, 2012: 187)

Resulta muy interesante la deontología de la profesión que se desprende de estas novelas. La competencia suele ser menos escrupulosa, menos humanista, favoreciendo lo ilícito y los fraudes de cualquier tipo. Prevalece lo justo sobre lo legal y los protagonistas intentan ayudar a sus clientes en todo lo que pueden, como en La mediadora:

Pues yo debo decirte que en todo esto hay una parte de secreto profesional. Yo soy abogada y también me debo a la ética de mi profesión. Lo que voy a proponerte es un proceso nuevo que te explicaré con detenimiento y en el cual tú tendrás tu parte, tu tarea, tus obligaciones, como yo tendré las mías... Pero no debes actuar por tu cuenta. Se acabaron las locuras, Agustín... Si aceptas este proceso, deberás guiarte en todo por mis indicaciones y no crear problemas. (Sánchez Adalid, 2015: 74)

Además, el abogado forma parte, por su dimensión social, de un abanico de profesiones con las que comparte intereses o relaciones. Esas profesiones parajurídicas - periodistas, policías, peritos, etc.- obligan a los que las ejercen a respetar cierta ética de confidencialidad y discreción, de ahí el interés para el lector de descubrir los misterios de ese mundo secreto.

Dentro de los bufetes, se encuentra también cierta forma de ideología en cuanto a lo que se espera de la justicia, una forma de distinguir el Bien y el Mal por así decirlo, en una división maniquea, en un primer momento, entre los justicieros y los criminales. Esta axiología depende mucho del código y las normas que se han de acatar. No obstante, esas normas no son exentas de cierto tipo de prejuicios y todo el proceso judicial queda muy codificado, con unos plazos que respetar, correos que redactar, entrevistas que hacer, etc. La presión del oficio - como gajes del oficio- es tremenda, aunque la visión positiva sobresale en estas novelas, en las que amistades auténticas son posibles, en unos bufetes de talla humana, con una solidaridad constructiva que pone en perspectiva la figura del abogado. En este sentido, esas novelas no son individualistas a pesar de las individualidades que se encuentran en ellas. Hacen reflexionar al lector que ha de pensar la justicia en nuestra sociedad contemporánea frente a la corrupción, la codicia, la violencia o el crimen organizado. 

a base de tópicos e ideas preconcebidas, para brindar une visión realista e irónica del ámbito profesional que parece surgir de una experiencia auténtica. Por lo tanto, el premio logra conseguir su objetivo de dar a conocer la profesión, aunque el prestigio conferido al abogado por la buena imagen transmitida por la ficción pueda aparecer como el resultado de un conflicto de intereses. De hecho, solo se premian obras bastante halagadoras, lo que no siempre es el caso en los thrillers judiciales de otras culturas.

Por último, cabe subrayar que este premio "profesional" es excepcional y representa un desafío para los actores de la abogacía. Es cierto que los abogados son más numerosos y más próximos en España que en otras partes del mundo. Sin embargo, esta vía de acceso a la cultura judicial, a su léxico y a sus mecanismos bajo forma de entretenimiento es una manera nueva no solo de ofrecer un testimonio del sustrato profesional sino también de hacer periodismo cuando el adstrato de especialidad prima.

\section{Últimas observaciones}

La figura del abogado es apta para asumir un papel didáctico en la medida en que a través de ella se tiene acceso al medio profesional de los despachos de abogados, a sus desafíos, sus problemas, y así, al léxico jurídico o los procedimientos judiciales. Estas novelas presentan una gran diversidad en cuanto a las especialidades abordadas y muestran diferentes aspectos del derecho, desde la conciliación al derecho de los negocios o incluso casos criminales.

Además, es de notar que el grado de tecnicidad constituye un síntoma de la FASP sin ser su único o principal criterio. La lengua especializada es una vertiente de la lengua, más visible, pero que se ve modificada por la tensión narrativa que la hace surgir. Si bien es cierto que este elemento lingüístico se puede diferenciar de los otros, y por ende, aislándolo, se podría considerar por sí mismo, forma parte de un conjunto superior. Por otra parte, la lengua de especialidad jurídica establece una relación de metonimia con la cultura que representa. En este reflejo sintetizador, se encuentra un gran potencial didáctico, hasta tal punto que se podría contemplar su uso en la enseñanza del español para fines específicos. En efecto, algunos fragmentos de la FASP jurídico-judicial son textos muy próximos a los de divulgación, con un funcionamiento en un modo explicativo y aclaratorio. La lengua especializada no se halla solo en la terminología, sino también en el discurso que forma la "enciclopedia" del dominio (Van der Yeught, 2016).

66

Aunque el Premio Abogados de Novela pueda tener el efecto perverso de creaciones "oportunas" que en cierta medida desnaturalizan el auténtico género de la FASP, el thriller jurídico-judicial ya existe como tal en España. Asimismo, este galardón cumple su designio de dar prestigio a la abogacía enseñando sus valores y su deontología, como recuerda cada convocatoria del premio:

Este galardón literario persigue la divulgación del mundo en que se desenvuelve la actividad de los abogados a través de obras de ficción con calidad literaria, que ayuden al lector a profundizar en el conocimiento de esta profesión, sus ámbitos de actuación, valores, proyección y transcendencia social de su función. (abogacia.es, 2012)

La presencia del derecho es doble en la literatura, la ley pero también la ética, es decir, frente a la legalidad, la legitimidad que humaniza los conflictos judiciales. Así es como la literatura permite pensar el derecho de una forma más ética, en función de aspectos 
sociales a veces olvidados al legislar, no resultando forzosamente justo lo legal. Pedro Talavera explica:

[...] el discurso jurídico es siempre institucional y formalizado: el derecho codifica la realidad, la institucionaliza, encerrándola dentro de un conjunto de rígidos conceptos y categorías y cercándola dentro de un sistema de obligaciones y prohibiciones. El discurso literario, por el contrario, carece de toda dimensión institucional, es siempre libre y creativo. (2006: 56)

Para terminar, este artículo ha permitido arrojar luz sobre un tipo de FASP marcado por la presencia cultural española. Se trata de novelas escritas por y para los españoles, aunque el éxito definitivo podría ser una posible adaptación audiovisual o su traducción a otros idiomas para una difusión internacional. La aclimatación del género anglosajón en España muestra la existencia de un nuevo realismo culturalista que se fundamenta en el mundo profesional, con la exploración del reflejo de su cultura y su lenguaje. Sin embargo, el género del thriller judicial podría también representar, como reproducción estética y catártica de la vida de la ciudad en el marco de nuestra sociedad, una versión actual de la tragedia.

\section{BIBLIOGRAFÍA}

ABogacia.es (2012), Premio Abogados de Novela, en línea en <http://www.abogacia.es/2012/07/03/ premio-abogados-de-novela/> (1 de junio de 2017).

ABogacia.es (2014a), Convocada la VI Edición del Premio Abogados de Novela, dotado con 50.000 euros, en línea en <http://www.abogacia.es/2014/08/04/convocada-la-vi-edicion-del-premio-abogados-denovela-dotado-con-50-000-euros/> (1 de junio de 2017).

ABogacia.es (2014b), Bases del premio Abogados de Novela 2015 - 6. ․e edición, en línea en <http:// www.abogacia.es/wp-content/uploads/2014/08/Bases-de-la-Convocatoria-VI-Premio-Abogadosde-Novela.pdf> (1 de junio de 2017).

BAJTín M. Mijaíl (2003), Problemas de la poética de Dostoievski (T. Bubnova, trad.), 2ª ed., México: FCE. BOTERo BERNAL Andrés (2002), "Encuentro con el derecho. Breve historia de la profesión y del saber jurídico", J. Ossa Londoño (dir.), Parcelas Horizontes: un encuentro con las disciplinas, Medellín: Biogénesis Fondo Editorial, 19-36.

BOTERO BERNAL Andrés (2008), "Derecho y Literatura: un nuevo modelo para armar. Instrucciones de uso", J. Calvo González (dir.), Implicación derecho literatura: Contribuciones a una Teoría literaria del Derecho, Granada: Comares, 29-39.

CALDERón Reyes (2013), El jurado número 10, Madrid: Ed. Martínez Roca.

CALVo GoNZÁLEZ José (2007), “Derecho y Literatura. Intersecciones instrumental, estructural e institucional”, Anuario de filosofía del derecho (24), Madrid: BOE, 307-332.

CALVo GONZÁLEZ José (2002), "Modelo narrativo del juicio de hecho: inventio y ratiocinatio", V. Zapaterio (dir.), Horizontes de la Filosofía del Derecho, Madrid: Universidad de Alcalá de Henares, II, 93-102. 
DWORKIN Ronald (1997), “Cómo el derecho se parece a la literatura”, C. Rodríguez (dir.), La decisión judicial: el debate Hart-Dworkin, Bogotá: Siglo del Hombre Editores, 143-180.

ESCRITORES.ORG (2014), VI edición del Premio Abogados de Novela (España), en línea en <https:// www.escritores.org/recursos-para-escritores/concursos-literario/11421-vi-edicion-del-premioabogados-de-novela-espana> (1 de junio de 2017).

GONZÁLEZ REY María Isabel (dir.) (2014), Outils et méthodes d'apprentissage en phraséodidactique, Bruselas: EME.

GuRRUCHAGA Carmen (2010), La prueba, Madrid: ed. Martínez Roca.

ISANI Shaeda (2004), “The FASP and the Genres within the Genre”, S. Isani \& M. Petit (dir.), Aspects de la fiction à substrat professionnel, Burdeos, Francia: Université Victor Segalen Bordeaux 2, 25-38.

ISANI Shaeda (2006), "Langue, lecture et littérature populaire : FASP et didactique des langues de spécialité”, Cahiers de l'APLIUT, XXV(3), 92-106.

ISANI Shaeda (2010a), "Dynamique spéculaire de la fiction à substrat professionnel et didactique des langues de spécialité”, ASp (58), 105-123.

ISANI Shaeda (dir.) (2010b), “La FASP, dix ans après...”, ILCEA (12), Grenoble: Université Grenoble Alpes, <https://ilcea.revues.org/442>.

MARTÍNEZ-ECHEVARRÍA Borja (2012), El bufete, Madrid: ed. Martínez Roca.

MARTíNEZ-eCheVARRía Borja (2015), “Palabra de John Grisham”, en línea en Expansión: <http:// www.expansion.com/blogs/elbufete/2015/05/28/palabra-de-john-grisham.html> (1 de junio de 2017).

Nussbaum Marta (1997), Justicia Poética (C. Gardini, trad.), Barcelona: ed. Andrés Bello.

Ost François (2004), Raconter la loi, París: Odile Jacob.

PETIT Michel (1999), “La fiction à substrat professionnel : une autre voie d'accès à l'anglais de spécialité”, ASp, la revue du GERAS (23/26), 57-81.

PETIT Michel (2004), “Quelques réflexions sur la fiction à substrat professionnel : du général au particulier”, S. Isani \& M. Petit (dir.), Aspects de la fiction à substrat professionnel, Burdeos, Francia: Université Victor Segalen Bordeaux 2, 3-23.

PETIT Michel (2006), “Les descripteurs du cadre : quelle conception de la langue de spécialité ?", F. Haramboure et al. (dir.), Travaux des journées 2006 de l'EA 2025, Burdeos, Francia: Université Victor Segalen Bordeaux 2, 14-29.

POSNER Richard A. (1996), Droit et littérature (P. Jouary et C. Hivet, trad.), París: PUF.

RICEUR Paul (1983, 1984, 1985), Temps et récit I, II, III, París: Seuil.

RIC๕EUR Paul (1995, 1995, 1996), Tiempo y narración I, II, III (A. Neira, trad.), México: Siglo XXI Editores.

ROGGERo Jorge (dir.) (2016), Derecho y Literatura: textos y contextos, Buenos Aires: Eudeba.

SÁNCHEZ ADALID Jesús (2015), La mediadora, Madrid: ed. Martínez Roca.

TALAVERA Pedro (2006), Derecho y Literatura, Granada: Comares.

VAN DER YEUGHT Michel (2016), “A proposal to establish epistemological foundations for the study of specialised languages”, Asp (69), 41-63. 
VillanUeVA PRIETo Darío (2011), “Los diálogos entre derecho y literatura (Un caso práctico: el informe Barral)”, M. Mª Otero Parga (dir.), Tópica, retórica y dialéctica en la jurisprudencia: estudios en homenaje a Francisco Puy, Santiago de Compostela: USC, 461-467.

\section{NOTAS}

1. Cabe destacar que en teoría todo lo extraliterario pasa a considerarse ficticio en el marco de la ficción. El Derecho es un campo un poco diferente que, como trasfondo referencial de algunas novelas, guarda cierta autonomía y se percibe, pues, desde la perspectiva de una casuística realista.

2. La traducción del original francés es nuestra: "peut être considéré comme ressortissant à la FASP tout texte de fiction commerciale à grand succès (i) relevant généralement du thriller spécialisé (juridique, médical, technologique, etc.), (ii) utilisant un milieu professionnel particulier non seulement comme cadre général de l'histoire mais aussi et surtout comme l'une des sources principales des ressorts de l'intrigue, (iii) exprimé dans une langue reproduisant les pratiques langagières (lexicales et discursives) de ce milieu, et (iv) généralement écrit par un auteur dont l'appartenance ou les liens avec ce milieu sont explicitement revendiqués" (2000: 173-174).

3. España cuenta con casi tres veces más abogados que Francia por ejemplo, 152954 frente a 63923 en 2016. Se podría hacer una correlación entre el número de abogados y la presencia de la FASP, ya que Estados Unidos tiene el récord del número de abogados, con cerca de un millón. España y Estados Unidos tienen la misma proporción de abogados con aproximadamente uno por cada 300 habitantes.

4. Este estudio se ciñe a la FASP jurídica formada en torno a este premio. Sin embargo, no cabe ninguna duda de que existen otros subgéneros de FASP en España con los que resultaría interesante contrastar esta aproximación al género.

5. Resultaría particularmente interesante ver la relación que puede existir entre estas novelas y las del maestro del género John Grisham, casi todas disponibles en colecciones de bolsillo de tipo "BestSeller" o "Éxitos".

6. Cf. "La esencia de la polifonía consiste precisamente en que sus voces permanezcan independientes y como tales se combinen en una unidad de un orden superior en comparación con la homofonía." (Bajtín, 2003: 38).

\section{RESÚMENES}

Este artículo se interesa por la emergencia de la FASP jurídica en España en el siglo XXI. Este fenómeno se hace visible con la creación del "Premio Abogados de Novela" que indica el reconocimiento del género a partir de 2010. Será la ocasión de presentar los criterios de la ficción con sustrato profesional tal como la definieron los investigadores pioneros en este campo, Michel Petit y Shaeda Isani. Por otra parte, trataremos de evidenciar las particularidades de la FASP jurídica española en sus dos vertientes, a la vez lengua y cultura de especialidad, así como sus características como género híbrido. Por último, se estudiará la representación del abogado y su 
deontología en unas de las obras galardonadas, subrayando así la importancia de la cuestión ética en la encrucijada entre Derecho y Literatura.

Cet article s'intéresse à l'émergence de la FASP juridique en Espagne au $\mathrm{xxI}^{\mathrm{e}}$ siècle. Ce phénomène a gagné en visibilité avec la création du « Premio Abogados de Novela » (Prix Avocats du roman) qui marque ainsi la reconnaissance du genre à partir de 2010. Ce sera l'occasion de présenter les critères de la fiction à substrat professionnel telle qu'elle a été définie par Michel Petit et Shaeda Isani, les chercheurs pionniers dans ce domaine. Par ailleurs, nous tenterons de mettre au jour les particularités de la FASP juridique espagnole, dans ses deux versants de langue et culture de spécialité, ainsi que ses caractéristiques en tant que genre hybride. Enfin, la représentation de l'avocat et de sa déontologie dans certaines œuvres primées sera étudiée et montrera combien la question éthique est importante à la croisée du droit et de la littérature.

This article addresses the emergence of legal FASP (profession-based fiction) in Spain in the $21^{\text {st }}$ century which gained visibility with the creation of the "Premio Abogados de Novela" prize (Lawyer Novel Prize) in 2010. After an introduction to the FASP genre as defined by Michel Petit and Shaeda Isani, the pioneering researchers in this field of LSP research, we highlight the particularities of Spanish legal FASP, looking at the aspects of specialized language and culture, as well as its characteristics as a hybrid genre. We next study fictional representation of lawyers and their code of ethics as projected in award-winning works and discuss the importance of the question of ethics at the crossroads of Law and Literature.

ÍNDICE

Palabras claves: Derecho y Literatura, FASP, Carmen Gurruchaga, Borja Martínez-Echevarría, Reyes Calderón, Jesús Sánchez Adalid

Keywords: Law and Literature, FASP, Carmen Gurruchaga, Borja Martínez-Echevarría, Reyes Calderón, Jesús Sánchez Adalid

Mots-clés: droit et littérature, FASP, Carmen Gurruchaga, Borja Martínez-Echevarría, Reyes Calderón, Jesús Sánchez Adalid

\section{AUTOR}

\section{THIERRY NALLET}

Université Grenoble Alpes, ILCEA4 